\title{
Anabases
}

ANABASES Traditions et réceptions de l'Antiquité

$6 \mid 2007$

Varia

\section{Alfredo JIMENO MARTÍNEZ, José Ignacio de la TORRE ECHÁVARRI, Numancia, símbolo e historia}

\section{Grégory Reimond}

\section{OpenEdition}

Journals

Édition électronique

URL : http://journals.openedition.org/anabases/3430

DOI : 10.4000/anabases.3430

ISSN : 2256-9421

Éditeur

E.R.A.S.M.E.

Édition imprimée

Date de publication : 1 octobre 2007

Pagination : 279-280

ISSN : $1774-4296$

\section{Référence électronique}

Grégory Reimond, «Alfredo Jimeno martínez, José Ignacio de la torre eChávarRi, Numancia, símbolo e historia », Anabases [En ligne], 6 | 2007, mis en ligne le 01 janvier 2012, consulté le 22 septembre 2020 URL : http://journals.openedition.org/anabases/3430 ; DOI : https://doi.org/10.4000/anabases.3430

Ce document a été généré automatiquement le 22 septembre 2020.

(c) Anabases 


\title{
Alfredo JIMENO MARTÍNEZ, José Ignacio de la TORRE ECHÁVARRI, Numancia, símbolo e historia
}

\author{
Grégory Reimond
}

\section{RÉFÉRENCE}

Alfredo JIMENO MARTÍNEZ, José Ignacio de la TORRE ECHÁVARRI,

Numancia, símbolo e historia, Madrid, Akal, 2005,

$269 \mathrm{p}$.

16,50 euros / ISBN 84-460-0934-X.

1 Certaines pages de l'Histoire Universelle sont restées ancrées dans la mémoire collective des nations sous forme de symboles autour desquels mythes, légendes et histoire s'entremêlent, parfois jusqu'à se confondre. L'histoire de l'Espagne ne fait pas exception à la règle. Songeons au légendaire peuplement de la péninsule par les fils de Noé, suite au Déluge, aux héros «nationaux» qui luttèrent contre l'envahisseur romain, aux figures éclairées des «empereurs hispaniques», au Cid, héros de la Reconquête, etc.

2 L'histoire protohistorique de l'Hispanie a, elle aussi, ses symboles. Dans l'imaginaire populaire, la culture ibérique reste sans doute attachée à l'image du buste, tant de fois reproduit et diffusé, de la Dame d'Elche. En revanche, évoquer le monde celtibère, et c'est le nom de Numance qui est sur toutes les lèvres, célèbre cité (dont les vestiges, redécouverts grâce aux fouilles archéologiques, se situent près de l'actuelle Soria) qui devint pour un temps le centre du processus de conquête de la péninsule par Rome. Bien décidée à lutter pour freiner l'impérialisme de l'Urbs, la ville assiégée résista à Scipion Émilien et ses troupes. Lorsque tout espoir de victoire s'évanouit, ses habitants préférèrent se donner la mort plutôt que de voir défiler l'imperator en vainqueur, lequel 
ne pardonna pas cet acte de bravoure qui assombrit son triomphe. Une fois prise, la cité fut détruite.

3 L'ouvrage d'Alfredo Jimeno (professeur de préhistoire à l'université Complutense de Madrid) et José I. de la Torre (collaborateur du Département d'histoire ancienne et de préhistoire de l'UCM) ne prétend pas retracer l'histoire de Numance, mais celle de son mythe, fondé sur des faits réels progressivement transformés, reconstruits selon les exigences idéologiques du moment. Partant des sources classiques, émanation des vainqueurs, narrant l'affrontement entre Celtibères et Romains (153-133 av. J.-C.), ces deux spécialistes nous proposent un ouvrage de synthèse, sous la forme d'un parcours historiographique construit autour de la question de l'utilisation idéologique de la geste de Numance. Au départ simple récit écrit par des vainqueurs volontiers disposés à louer la lutte et la fin héroïques des Numantins, l'histoire du siège se convertit peu à peu en une pièce essentielle de la mémoire collective de l'Espagne impériale (il s'agit alors de légitimer le pouvoir de la dynastie des Habsbourg), puis de l'État-nation libéral. Loin de démonter ce récit légendaire, les auteurs prétendent au contraire expliquer pas à pas les raisons et les étapes de la conversion de cette page de l'Histoire en un puissant mythe identitaire atemporel, capable de dépasser les clivages idéologiques.

Plusieurs perspectives sont abordées: celle qu'offre l'étude des discours historiques (Chroniques, Histoires Générales, etc.), mais aussi celle de la littérature, des Anciens comme des Modernes (la tragédie de Cervantès, El Cerco de Numancia, par exemple), celle de l'histoire de l'art (le thème de la destruction de Numance donne lieu à une abondante production artistique, comme le tableau d'Alejo Vera en 1881, El último día de Numancia, abondamment reproduit dans les manuels scolaires), sans oublier les données fournies par l'archéologie, les premières fouilles débutant au début du XIX siècle et se poursuivant jusqu'à nos jours, malgré de longues périodes d'interruption et « d'oubli » du site.

Outre cette approche pluridisciplinaire, qu'en est-il de l'organisation de l'ouvrage ? Par commodité, les auteurs ont choisi une présentation chronologique qui s'ouvre sur un bref historique de la geste numantine, avant de s'attacher à l'étude de l'acte de naissance du mythe, signé par l'historiographie classique, et à son devenir au cours de l'époque médiévale (chapitres 2 et 3). Les trois parties suivantes analysent la polémique surgie entre érudits autour de la situation exacte de la cité, sa place dans les premières élaborations d'histoire de l'Espagne, destinées d'abord à glorifier et légitimer la monarchie habsbourgeoise, puis à configurer l'idée historique de lo español, à partir du $\mathrm{xVIII}^{\mathrm{e}}$ siècle, ce Siècle des Lumières qui voit surgir la Nation sur la scène de l'Histoire. La geste de Numance devient alors un puissant argument capable de souligner l'esprit patriotique et d'indépendance des habitants de la péninsule, héritiers des martyrs numantins $\mathrm{du} \mathrm{II}$ e siècle avant J.-C. Dès lors, le mythe est constamment sollicité afin de participer à la construction des discours identitaires nationaux et provinciaux, que ce soit par l'historiographie romantique, le mouvement régénérationiste surgi suite à la défaite de 1898 (qui révèle l'existence d'une crise identitaire nationale profonde), ou même par l'historiographie nationale-catholique (chapitres 7 à 9). L'ouvrage se clôt sur un tableau de la situation actuelle en matière de connaissances, de recherche, de mise en valeur et de diffusion auprès du grand public du site du Cerro de La Muela, dans un contexte bouleversé par la restructuration territoriale d'une Espagne très décentralisée en matière de politiques culturelles (chapitres 10 et 11). Précisons, en outre, que les auteurs ont réuni l'essentiel de la bibliographie concernant l'historiographie de 
Numance, les treize pages de références proposées constituant un outil de travail précieux.

6 Une histoire de la construction progressive et de l'utilisation du mythe numantin à travers les âges, de l'Hispanie romaine jusqu'à l'Espagne des Régions Autonomes, voilà ce que le lecteur trouvera dans cet ouvrage passionnant et riche en documents iconographiques.

\section{AUTEURS}

\section{GRÉGORY REIMOND}

Université de Toulouse II-Le Mirail

g.p.reimond-pandele@hotmail.com 